\title{
A research report on "positive prevention" intervention in two ethnic habitats along the border with myanmar in yunnan
}

\author{
Yan Guo, Bin Su* \\ From $16^{\text {th }}$ International Symposium on HIV and Emerging Infectious Diseases \\ Marseille, France. 24-26 March 2010
}

\begin{abstract}
Background
"Positive Prevention", which targets on people living with HIV/AIDS (PLHIV), aims to improve their life quality and living standard, protect their families and communities, and help reducing HIV infection. This report evaluates a "positive prevention" training intervention project in Ruili and Longchuan of ethnic group Counties along the border with Myanmar in Yunnan province, China.
\end{abstract}

\section{Methods}

312 HIV-positive volunteers of ethnic groups enrolled in invention cohort in Ruili had received "Positive Prevention" training. In contract, $308 \mathrm{HIV}$-positive volunteers of similar ethnic groups were enrolled in non intervention cohort in Longchuan after baseline surveys for the two groups. 12 months after the training, 203 participants in Ruili and 274 participants in Longchuan were traced respectively. Qualitative and quantitative methods of focused group discussion, in depth interview and in site observation were used to assess their health knowledge, health belief, health behavior, and health outcome.

\section{Results}

Demographic and occupationalcompositions of the participants from the two counties are very similar. The group in Ruili resulted in significant increase of health knowledge, improvement in perceived susceptibility and severity of diseases such as STIs and hepatitis, and perceived benefits of health behaviors, and willingness to take a role in the HIV/AIDS prevention actions. Among Ruili participants, condom protected intercourse in the latest sexual behavior increased dramatically from $77.97 \%$ at baseline to $97.69 \%\left(\chi^{2}=21.438, \mathrm{P}=0.000<\right.$ 0.05). New HCV incidence rate was $8.0 \%$ in Longchuan and $3.97 \%$ in Ruil while new HBV incidence rate in Longchuan was $1.96 \%$ and $0.98 \%$ in Ruili. The low new incidence rate in Ruili was attributed to the changes as a result of the intervention.

\section{Discussion}

This "Positive Prevention" training intervention has improved health knowledge and health belief of intervened PLHIV and reduced their high risk behaviors to some extent. It imposes an impact on prevention of new infection for PLHIV. The lessons learnt from this project can be used for options to improve "Positive Prevention" strategies in terms of selection of target population, design of intervention activities, approaches and sustainability in ethnic habitat communities.

Published: 11 May 2010

doi:10.1186/1742-4690-7-S1-P96

Cite this article as: Guo and $\mathrm{Su}$ : A research report on "positive prevention" intervention in two ethnic habitats along the border with myanmar in yunnan. Retrovirology 2010 7(Suppl 1):P96.

\footnotetext{
* Correspondence: subinait@yahoo.com

Yunnan Daytop Drug Abuse Treatment and Rehabilitation Center, Kunming, PR China
} 